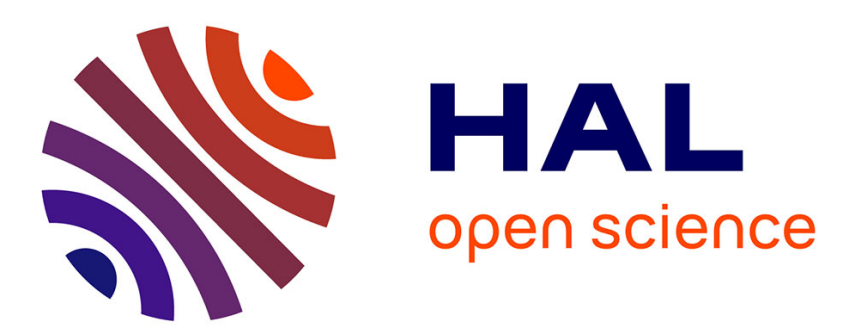

\title{
Réactions différentielles du tabac à 9 espèces de Phytophthora
}

\author{
Philippe Bonnet, G. Rousse
}

\section{To cite this version:}

Philippe Bonnet, G. Rousse. Réactions différentielles du tabac à 9 espèces de Phytophthora. Agronomie, 1985, 5 (9), pp.801-808. hal-00884814

\section{HAL Id: hal-00884814 https://hal.science/hal-00884814}

Submitted on 1 Jan 1985

HAL is a multi-disciplinary open access archive for the deposit and dissemination of scientific research documents, whether they are published or not. The documents may come from teaching and research institutions in France or abroad, or from public or private research centers.
L'archive ouverte pluridisciplinaire HAL, est destinée au dépôt et à la diffusion de documents scientifiques de niveau recherche, publiés ou non, émanant des établissements d'enseignement et de recherche français ou étrangers, des laboratoires publics ou privés. 


\title{
Réactions différentielles du tabac à 9 espèces de Phytophthora
}

\author{
Philippe BONNET \\ avec la collaboration technique de G. RoussE \\ I.N.R.A., Station de Pathologie végétale, bd du Cap, B.P. 2078, F 06606 Antibes
}

Vingt souches de Phytophthora (tabl. 1) ont été mises en culture stationnaire durant $21 \mathrm{j}$, à $24{ }^{\circ} \mathrm{C}$, sur un milieu liquide (PLICH \& RUDNICKI, 1979). Après élimination du mycélium, on a testé la toxicité des divers filtrats de culture dilués au $1 / 10$ vis-à-vis de feuilles détachées de tabac; les filtrats des 15 souches appartenant à 8 espèces de Phytophthora non pathogènes sur tabac induisent tous, dans ce cas, des symptômes sévères de toxicité (tabl. 2). Lorsque ces mêmes filtrats sont appliqués à de jeunes plants de tabac par trempage racinaire on peut distinguer deux groupes de souches suivant l'intensité des symptômes : avec les 4 espèces à forte toxicité ( $P$. megasperma, cinnamomi, cryptogea et drechsleri), il apparaît en $20 \mathrm{~h}$ des nécroses foliaires importantes et le plant flétrit, tandis que les 4 autres espèces ( $P$. cactorum, parasitica, capsici et citrophthora), à toxicité plus faible, ne donnent des lésions que sur les feuilles inférieures et n'entraînent pas de flétrissement du plant (tabl. 3). Enfin l'inoculation, sur tige de tabac décapité, du mycélium de ces 15 souches entraîne également, 2 ou $3 \mathrm{j}$ après, l'apparition de taches nécrotiques ; pour les espèces à forte toxicité, les zones nécrosées sont importantes et concernent la majorité des feuilles; pour celles à toxicité faible, les symptômes nécrotiques foliaires sont discrets et erratiques si le plant inoculé est placé sous $16 \mathrm{~h}$ de lumière mais s'accusent très nettement s'il reçoit $8 \mathrm{~h}$ de lumière (tabl. 4). Aucune réaction toxique sur feuilles n'a pu être observée avec les 5 souches de Phytophthora parasitica var. nicotianae, que ce soit avec les filtrats de culture ou par inoculation sur tige. Ces résultats diffèrent de ceux obtenus par CsinOs \& HENDRIX (1977 à 1979), surtout en ce qui concerne les souches non pathogènes à faible toxicité. L'ensemble des Phytophthora non pathogènes incompatibles apparaissant comme seuls capables d'induire des réactions toxiques systémiques, peut-on envisager le concept de " toxine d'incompatibilité "?

Mots clés additionnels : Filtrats culture, inoculation.

Twenty strains of Phytophthora (table 1) were grown on liquid media (Plich \& RUdnicki, 1979) at $24{ }^{\circ} \mathrm{C}$. After 21 days of stationary culture, the different culture filtrates were separated from the mycelium and their toxicity towards detached tobacco leaves and whole tobacco plants tested. With 15 strains belonging to 8 species of Phytophthora non-pathogenic to tobacco ( $P$. cactorum, parasitica, capsici, citrophthora, megasperma, cinnamomi, cryptogea and drechsleri), the tenfold-diluted culture filtrates induced severe symptoms of toxicity on detached tobacco leaves of Nicotiana tabacum var. « Xanthi » and var. "Samsun » (table 2). When forty days old tobacco plants were placed in the same filtrates, after the root tips had been cut off, it was possible to distinguish two types of strains according to the intensity of symptoms ; with the " highly toxic " (H.T.) strains (drechsleri, cryptogea, megasperma and cinnamomi) leaves showed high necrosis and a sudden wilt of the plants occurred in $20 \mathrm{~h}$, while with the « weakly toxic » (W.T.) strains only the lower leaves exhibited symptoms, and the plants did not wilt if they were transferred into water after $20 \mathrm{~h}$ (table 3 ). In another experiment, mycelium of the 15 strains was inoculated into the stem of detopped tobacco plants; two or three days after inoculation with (H.T.) strains, necrotic areas were clearly visible on the lamina of most leaves. With (W.T.) strains, the necrotic symptoms on leaves were weak and erratic of tobacco plants were kept under $16 \mathrm{~h}$ illumination after inoculation ; if the light period was reduced to $8 \mathrm{~h}$, the necrotic symptoms became very strong (table 4). No toxic reaction on leaves was observed with 5 strains of $P$. parasitica var. nicotianae either using culture filtrates on detached leaves and rooted plants or after mycelium inoculation onto the stem. Our results differ from those of CSINOS \& $\operatorname{HENDRIX}(1977,1978,1979)$ especially in respect to (W.T.) strains, possibly due to the use of culture filtrates (instead of mycelium extracts) and of the stem inoculations on detopped plants. Thus, Phytophthora strains cause more or less severe systemic toxicity symptoms on tobacco leaves, the only exception being seemingly those which are pathogenic to tobacco. This could suggest the concept of " incompatibility toxin(s) ". 


\section{INTRODUCTION}

Dans les relations hôte-parasite, le couple Phytophthora-Tabac présente un exemple intéressant de spécialisation parasitaire puisque seule l'espèce P. parasitica (Dast.) var. nicotianae (B. de Haan) Tucker est pathogène sur cette plante : envahissant racines et tissus caulinaires, elle provoque la maladie du « pied noir » (black shank) et la mort de la plante. Sur ce couple plante-parasite, CSINOS \& HENDRIX (1977a, b, c, 1978 ; CSINOS, 1979) ont pu déterminer par inoculations 3 groupes d'interactions. Dans le $1^{\mathrm{er}}$, concernant l'espèce pathogène $P$. parasitica var. nicotianae, la tige est envahie mais il n'apparait aucune lésion nécrotique foliaire; chez les 2 autres groupes les lésions sur tige sont nulles ou limitées mais au niveau foliaire, l'un des groupes $(P$. parasitica Dast., $P$. cinnamomi Rands.) ne donne aucun symptôme tandis que l'autre ( $P$. cryptogea Pethybr. \& Laff., $P$. drechsleri Tucker, $P$. megasperma Drechsl., P. erythroseptica Pethybr.) induit à distance de fortes lésions nécrotiques. Enfin les broyats mycéliens des différentes espèces, appliqués à des feuilles détachées ou à de jeunes plants, donnent des résultats parallèles aux inoculations puisque seul le $3^{\mathrm{e}}$ groupe apparaît toxique.

Dans la combinaison hôte-parasite tabac-Phytophthora, l'espèce $P$. cryptogea apparaît donc comme non pathogène (HENDRIX, 1976) mais susceptible de produire une substance, présente dans les broyats mycéliens et les filtrats de culture (CSINOS \& HENDRIX, 1977c), toxique vis-à-vis de cette plante nonhôte (phytotoxine).

Cette même espèce $P$. cryptogea étant en revanche pathogène sur gerbera (MIDDLETON et al., 1944 ; SCHOLTEN, 1970 ; GARIBALDI, 1975 ; BONNET et al., 1980 ; ORLIKOWSKY \& REJMAN, 1980 ; ATHANASSIOU et al., 1981) plusieurs souches furent mises en culture suivant la technique de CSINOS \& HENDRIX (1977) pour mettre en évidence une éventuelle toxine active sur la plante-hôte gerbera (pathotoxine); quelques autres espèces de Phytophthora furent prises pour comparaison $(P$. parasitica var. nicotianae, parasitica, cactorum, cinnamomi) et l'effet toxique des divers filtrats de culture fut donc testé à la fois sur feuilles détachées de gerbera et de tabac afin de vérifier si les résultats de CSINOS \& HENDRIX se retrouvaient avec nos souches.

Sur feuilles de gerbera, nous n'avons pu observer aucun symptôme reproductible de toxicité quel que soit le filtrat utilisé. Sur feuilles détachées de tabac, le filtrat de $P$. parasitica var. nicotianae ne présente aucune toxicité, ceux de $P$. cryptogea entraînant de fortes réactions nécrotiques : ces résultats se montrent parfaitement conformes à ceux de CSINOS. Par contre, avec les filtrats de culture des espèces du $2^{\mathrm{e}}$ groupe ( $P$. parasitica et $P$. cinnamomi) et de l'espèce $P$. cactorum nous observons un léger effet toxique et les 3 espèces, inoculées sur pétiole de tabac, donnent aussi des réactions nécrotiques foliaires, souvent discrètes et d'apparition irrégulière. Nous avons donc sélectionné une vingtaine d'isolats de Phytophthora pathogènes et non pathogènes sur tabac afin de préciser sur cette plante - tant par utilisation de filtrats de culture que par inoculations - l'induction de lésions nécrotiques foliaires.

\section{MATÉRIEL ET MÉTHODES}

\author{
A. Phytophthora : isolats et cultures en milieux \\ liquides
}

\section{Isolats}

Le choix des 20 isolats (tabl. 1) a été fait de manière à répondre à plusieurs exigences : avoir en référence des espèces utilisées par CSINOS, inclure diverses espèces étudiées pour leur pathotoxine ( $P$. citrophthora, BREIMAN \& BARASH, $1981 ; P$. cactorum, Plich \& RUDNICKI, 1979) et avoir, par espèce, 2 souches isolées de plantes-hôtes différentes.

\section{Techniques de culture en milieux liquides}

Dans une $1^{\text {re }}$ étape, on a cultivé 11 souches suivant la technique de CSINOS \& HENDRIX (1977a) : ensemencement de $50 \mathrm{ml}$ de milieu par $1 \mathrm{ml}$ de broyat mycélien, culture à $24{ }^{\circ} \mathrm{C}$, d'abord stationnaire $(2 \mathrm{j})$ puis agitée $(150 \mathrm{tr} / \mathrm{mn})$ durant $5 \mathrm{j}$; après élimination du mycélium, le filtrat de culture est stérilisé par filtration (Millipore $0,22 \mu \mathrm{m}$ ) et sa toxicité sur feuilles détachées de tabac est testée par dilution au 1/10 en tampon Gomori $(\mathrm{pH} 4)$ de manière à homogénéiser les $\mathrm{pH}$ des divers extraits au moment du test biologique (tabl. 2A).

Dans une $2^{e}$ étape, on a comparé la toxicité des filtrats de 17 souches obtenus par 2 techniques différentes : milieu de CSINOS \& HENDRIX et culture agitée de $7 \mathrm{j}$, milieu $\mathrm{n}^{\circ} 5$ de PLICH \& RUDNICKI (1979) et culture stationnaire de $21 \mathrm{j}$ (tabl. 2B) ; dans ce cas, les milieux sont distribués à raison de $25 \mathrm{ml}$ en flacons de $250 \mathrm{ml}$ et ensemencés par 2 pastilles $(4 \mathrm{~mm})$ de culture mycélienne prélevées sur milieu malt-gélosé. En fin de culture les filtrats, débarrassés du mycélium, sont ramenés à pH 6 , stérilisés par filtration $(0,22 \mu \mathrm{m})$ et testés au 1/10 par dilution en eau distillée.

Dans un $3^{\mathrm{e}}$ temps, pour 20 souches de Phytophthora, on a refait des cultures sur milieu PLICH \& RUDNICKI (pH 6), distribué à raison de $100 \mathrm{ml}$ en fioles de Roux, autoclavé à $115^{\circ} \mathrm{C}$ pendant $30 \mathrm{mn}$ et ensemencé par 4 pastilles $(4 \mathrm{~mm})$ de culture mycélienne. Après $21 \mathrm{j}$ de culture stationnaire à $24{ }^{\circ} \mathrm{C}$, on a mesuré pour chaque culture le poids sec de mycélium obtenu et le $\mathrm{pH}$ final du filtrat de culture ; ce dernier, réajusté à $\mathrm{pH} 6$, est stérilisé $(0,22 \mu \mathrm{m})$ et stocké au froid ; le test de toxicité est fait par dilution au 1/10 dans l'eau distillée (tabl. 2C).

\section{B. Tests de toxicité des filtrats de culture}

\section{Sur les feuilles détachées de tabac}

Les feuilles sont prélevées sur des tabacs (Nicotiana tabacum var. "Xanthi» ou «Samsum ») élevés en serre ; chaque feuille est pesée $(\mathrm{Po})$ et le pétiole, préalablement incisé longitudinalement sur $2 \mathrm{~mm}$ environ, est plongé dans $10 \mathrm{ml}$ de filtrat de culture brut ou dilué au $1 / 10$. Après $24 \mathrm{~h}$ de séjour à l'étuve (obscurité, $24^{\circ} \mathrm{C}$ ), on note les symptômes apparents de flétrissement et la feuille, essuyée, est à nouveau pesée 
TABLEAU 1

Caractéristiques des isolats de Phytophthora. Espèces étudiées par CSINOS \& HENDRIX et données pour non toxiques (*) ou toxiques (**). Main characteristics of Phytophthora isolates; non toxic species (*) and toxic species (**) according to CSINOS \& HENDRIX.

\begin{tabular}{|c|c|c|c|c|c|}
\hline $\begin{array}{c}\text { Espèces } \\
\text { (groupes WATERHoUSE) }\end{array}$ & $\begin{array}{l}N^{\circ} \\
\text { Isolat }\end{array}$ & Plante & $\begin{array}{l}\text { Isolement } \\
\text { Pays }\end{array}$ & Année & $\begin{array}{c}\text { Types compatibilité } \\
\text { (races) }\end{array}$ \\
\hline $\begin{array}{l}\text { P. cactorum (P. CAC.) } \\
\text { (I) }\end{array}$ & $\begin{array}{l}195 \\
177\end{array}$ & $\begin{array}{l}\text { Fragaria } \\
\text { Pommier }\end{array}$ & $\begin{array}{l}\text { France } \\
\text { France }\end{array}$ & $\begin{array}{l}1978 \\
1976\end{array}$ & \\
\hline $\begin{array}{l}\text { P. parasitica } \\
\text { var. nicotianae } \\
(\text { P. NIC.) } \\
\text { (II) }\left(^{*}\right)\end{array}$ & $\begin{array}{l}180 \\
181 \\
182 \\
183 \\
184\end{array}$ & $\begin{array}{l}\text { Tabac } \\
\text { Tabac } \\
\text { Tabac } \\
\text { Tabac } \\
\text { Tabac }\end{array}$ & $\begin{array}{l}\text { U.S.A. (IMI 77972) } \\
\text { U.S.A. } \\
\text { U.S.A. } \\
\text { U.S.A. } \\
\text { U.S.A. }\end{array}$ & & $\begin{array}{l}\mathrm{A}_{2} \\
\left.\mathrm{~A}_{1} \text { (Race } 1\right) \\
\left.\mathrm{A}_{2} \text { (Race } 1\right) \\
\left.\mathrm{A}_{2} \text { (Race } 2\right) \\
\left.\mathrm{A}_{2} \text { (Race } 2\right)\end{array}$ \\
\hline $\begin{array}{l}\text { P. parasitica (P. PAR.) } \\
\text { (II) }\left(^{*}\right)\end{array}$ & $\begin{array}{l}26 \\
44\end{array}$ & $\begin{array}{l}\text { Dianthus } \\
\text { Citrus }\end{array}$ & $\begin{array}{l}\text { France } \\
\text { Corse }\end{array}$ & $\begin{array}{l}1971 \\
1972\end{array}$ & $\begin{array}{l}\mathbf{A}_{2} \\
\mathbf{A}_{1}\end{array}$ \\
\hline $\begin{array}{l}\text { P. capsici (P. CAP.) } \\
\text { (II) }\end{array}$ & $\begin{array}{l}140 \\
147\end{array}$ & $\begin{array}{l}\text { Tomate } \\
\text { Poivron }\end{array}$ & $\begin{array}{l}\text { France } \\
\text { France }\end{array}$ & 1974 & $\begin{array}{l}\mathbf{A}_{2} \\
\mathbf{A}_{1}\end{array}$ \\
\hline $\begin{array}{l}\text { P. citrophthora (P. CIT.) } \\
\text { (II) }\end{array}$ & $\begin{array}{l}232 \\
233\end{array}$ & $\begin{array}{l}\text { Citrus } \\
\text { Citrus }\end{array}$ & $\begin{array}{l}\text { Corse } \\
\text { Corse }\end{array}$ & $\begin{array}{l}1978 \\
1981\end{array}$ & $\begin{array}{l}\mathbf{A}_{1} \\
\mathbf{A}_{1}\end{array}$ \\
\hline $\begin{array}{l}\text { P. megasperma (P. MEG.) } \\
(\mathrm{V})\left({ }^{* *}\right)\end{array}$ & $\begin{array}{l}203 \\
151\end{array}$ & $\begin{array}{l}\text { Daucus } \\
\text { Forsythia }\end{array}$ & $\begin{array}{l}\text { France } \\
\text { France }\end{array}$ & $\begin{array}{l}1981 \\
1975\end{array}$ & \\
\hline $\begin{array}{l}\text { P. cinnamomi (P. CIN.) } \\
\quad(\mathrm{VI})\left({ }^{*}\right)\end{array}$ & $\begin{array}{l}122 \\
127\end{array}$ & $\begin{array}{l}\text { Chamaecyparis } \\
\text { Azalea }\end{array}$ & $\begin{array}{l}\text { France } \\
\text { France }\end{array}$ & & $\begin{array}{l}\mathbf{A}_{1} \\
\mathbf{A}_{1}\end{array}$ \\
\hline $\begin{array}{l}\text { P. cryptogea (P. CRY.) } \\
\text { (VI) }(* *)\end{array}$ & $\begin{array}{r}52 \\
192\end{array}$ & $\begin{array}{l}\text { Gerbera } \\
\text { Medicago }\end{array}$ & $\begin{array}{l}\text { France } \\
\text { Grèce }\end{array}$ & 1972 & $\begin{array}{l}A_{1} \\
A_{1}\end{array}$ \\
\hline $\begin{array}{l}\text { P. drechsleri (P. DRE.) } \\
\text { (VI) }\left({ }^{* *}\right)\end{array}$ & 165 & Chrysanthème & Argentine & & \\
\hline
\end{tabular}

(P24). La toxicité est exprimée par le rapport Po - P24

\section{Po}

\begin{tabular}{|c|c|c|c|c|}
\hline $\begin{array}{l}\text { Variations } \\
\text { de poids }\end{array}$ & +15 à $0 \quad 0,1$ à -5 & $-5,1 \grave{a ̀}-10$ & $-10,1$ à -30 & $-30,1$ à -65 \\
\hline Toxicité & 0 & t & $+t$ & $+t+$ \\
\hline
\end{tabular}

Une seconde lecture est faite après $40 \mathrm{~h}$ environ d'incubation.

\section{Trempage racinaire de plants entiers de tabac}

On a utilisé des plants de tabac (var. « Xanthi») élevés en terrine et en serre, âgés de $40 \mathrm{j}$ environ. Les plants sont sortis du substrat, les racines sont soigneusement lavées et on coupe l'extrémité du système racinaire. Le plant est pesé $(\mathrm{Po})$ et le système racinaire est mis à tremper dans $15 \mathrm{ml}$ de filtrat de culture (milieu Plich dilué au $1 / 10$ ). Après $24 \mathrm{~h}$ d'incubation $\left(24^{\circ} \mathrm{C}-16 \mathrm{~h}\right.$ lumière), on note les symptômes de toxicité (nécroses foliaires, flétrissement) puis le plant est essuyé et repesé (P24) ; le système racinaire est alors lavé à l'eau distillée, le plant est remis dans un flacon d'eau distillée et placé dans des conditions d'environnement identiques $\left(24{ }^{\circ} \mathrm{C}-16 \mathrm{~h}\right.$ lumière) pour observations ultérieures.

\section{Tests d'inoculation des champignons sur plants de tabac}

On a utilisé un lot de tabac (var. «Xanthi ») âgé de $70 \mathrm{j}$ et élevé en serre en jours courts (décembre - janvier). Une partie des plants a d'abord été placée pendant $8 \mathrm{j}$ dans une chambre climatisée à $23-24^{\circ} \mathrm{C}$ et $16 \mathrm{~h}$ de lumière, inoculée puis laissée dans ces mêmes conditions d'environnement (A). Une autre partie des plants est restée en serre, a été inoculée, puis placée à $23^{\circ} \mathrm{C}$ avec $8 \mathrm{~h}$ de lumière (B). Dans tous les cas, l'inoculation est faite en coupant la partie apicale du plant et en plaçant sur la section de tige une pastille de culture mycélienne prélevée en bordure d'une culture sur milieu malt-gélosé ; un capuchon de papier aluminium est placé sur l'inoculum afin d'éviter le desséchement trop rapide de ce dernier. Les symptômes sur tiges (envahissement) et sur feuilles (nécroses du limbe foliaire) sont notés après 3 et $10 \mathrm{j}$.

\section{RÉSULTATS}

\section{A. Feuilles détachées}

Cultivés sur milieu CSINOS (tabl. 2A), les 11 isolats de Phytophthora donnent des filtrats de culture peu toxiques à la dilution $1 / 10$, sauf pour les 2 isolats de $P$. cryptogea ; par contre, non dilués, la quasi- 


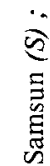

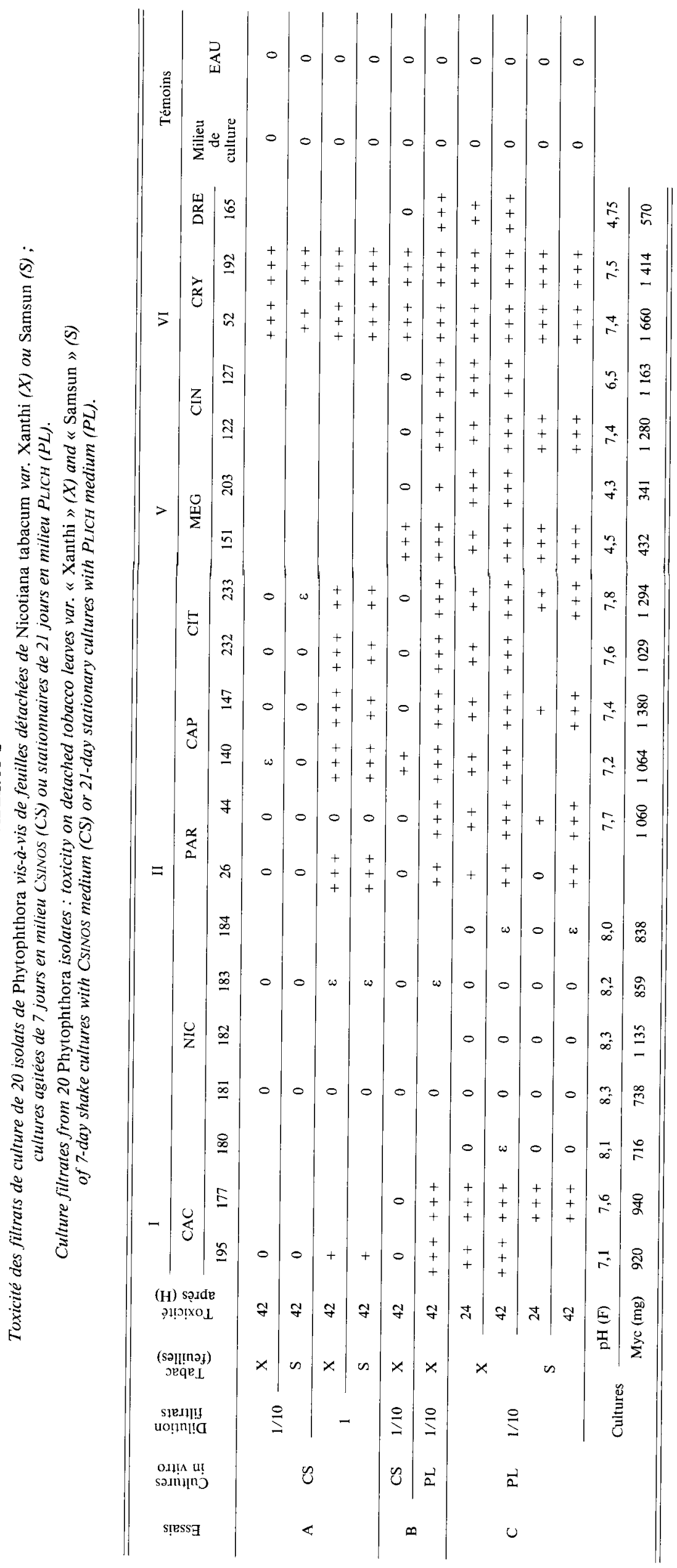


totalité des filtrats apparaît toxique, exception faite des 2 isolats de l'espèce parasite $P$. parasitica var. nicotianae. La comparaison, pour 17 souches, des filtrats de culture obtenus par 2 techniques différentes (tabl. 2B) fait apparaître - à dilution du $1 / 10$ - une toxicité nettement plus accusée avec le milieu PLICH. Enfin, cultivées sur ce dernier milieu, les 15 souches non pathogènes sur tabac donnent toutes des filtrats de culture toxiques sur feuilles détachées de tabac (var. "Xanthi » et var. "Samsum »), les seuls filtrats non toxiques étant ceux des 5 souches de l'espèce pathogène sur tabac (tabl. 2C). On peut noter que les $\mathrm{pH}$ en fin de culture $[\mathrm{pH}(\mathrm{F})]$ des 5 souches de $P$. parasitica var. nicotianae sont les plus élevés (supérieurs à $\mathrm{pH}$ 8) mais que l'on trouve dans le cas des filtrats toxiques aussi bien des souches à pH final bas et à faible rendement mycélien ( $P$. megasperma, $P$. drechsleri) que l'inverse ( $P$. citrophthora) ; il ne semble donc pas y avoir de corrélation directe entre ces deux caractéristiques des cultures et la toxicité de leurs filtrats sur tabac.

\section{B. Par trempage racinaire}

Les résultats obtenus après trempage racinaire des plants dans les filtrats de culture (dilution 1/10) permettent de faire deux remarques (tabl. 3). Après $24 \mathrm{~h}$, les plants ayant trempé dans les filtrats de culture de $P$. parasitica var. nicotianae ne présentent aucun symptôme de nécrose foliaire et n'ont subi qu'une très faible perte de poids (moins de 4 p. 100) ; par contre, les plants placés dans les autres filtrats ont tous subi des pertes de poids importantes allant de 19 à 49 p. 100 ; on retrouve donc ici le résultat global du test sur feuille détachée. Par ailleurs, l'observation des symptômes nécrotiques obtenus sur feuilles et l'évolution ultérieure des plants placés dans les filtrats des souches non parasites sur tabac font apparaître deux groupes. Avec les souches des groupes V et VI de WATERHOUSE (1963), la quasi-totalité des feuilles des plants est touchée et présente un noircissement des nervures principales et secondaires; les plants sont totalement flétris après $2 \mathrm{j}$. Par contre, avec les 4 espèces $P$. cactorum, parasitica, capsici et citrophthora, on constate des nécroses surtout sur les feuilles de base (ces nécroses forment des plages dans le limbe foliaire) et les plants, gardant leur partie apicale verte, survivent jusqu'au $8^{\mathrm{e}}$ j sans subir une diminution sensible de poids entre le $2^{\mathrm{e}}$ et le $8^{\mathrm{e}} \mathrm{j}$.

\section{Par inoculation sur tige}

Lors de l'inoculation des diverses souches de Phytophthora sur tige de tabac (tabl. 4), on constate que les souches de $P$. parasitica var. nicotianae envahissent les tiges inoculées en donnant des nécroses de 20 à $35 \mathrm{~mm}(++)$ en $3 \mathrm{j}$ et que ces nécroses vont évoluer ultérieurement (évolution + ) ; aucun symptôme nécrotique n'apparaît sur limbe foliaire et ce quelles que soient les conditions d'éclairement. Il faut noter que la souche 180 , identifiée comme $P$. parasitica var. nicotianae, apparaît ici comme non pathogène (aucune lésion sur tige) mais ne donne aucune lésion sur feuille.
Toutes les autres souches montrent un envahissement de la tige le plus souvent limité à quelques $\mathrm{mm}$ ( $\varepsilon$ ) ; dans quelques cas, l'envahissement est plus accusé, de l'ordre de 10 à $15 \mathrm{~mm}(+)$ au $3^{\mathrm{e}} \mathrm{j}$ mais la nécrose est bloquée vers le $4^{\mathrm{e}} \mathrm{j}$ (évolution 0 à entre 3 et $10 \mathrm{j}$ ). Quant aux symptômes foliaires provoqués par les 15 souches de Phytophthora non pathogènes sur tabac, on peut distinguer 2 groupes suivant les conditions de lumière auxquelles sont soumis les plants. Inoculées à des plants placés sous $16 \mathrm{~h}$ d'éclairement (tabl. 4A), les 4 espèces $P$. megasperma, cinnamomi, cryptogea et drechsleri font apparaître des symptômes nécrotiques foliaires très prononcés (majorité des feuilles avec nécroses allant du 1/4 à la quasitotalité de la feuille); avec les 4 autres espèces, les nécroses foliaires sont absentes ou beaucoup plus discrètes (nécroses ponctuelles sur 1 ou 2 feuilles). Par contre, l'inoculation des espèces $P$. cactorum, parasitica, capsici et citrophthora à des plants placés sous $8 \mathrm{~h}$ d'éclairement fait apparaître des symptômes nécrotiques foliaires très nets (tabl. 4B); on peut remarquer d'ailleurs que les 3 souches de $P$. megasperma (203), cinnamomi (122) et cryptogea (192) donnent, dans ces conditions, des réactions encore plus violentes qu'avec $16 \mathrm{~h}$ d'éclairement.

\section{DISCUSSION ET CONCLUSION}

On peut faire 3 remarques sur les résultats obtenus concernant les réactions toxiques différentielles observées sur tabac entre, d'une part, l'espèce parasite compatible ( $P$. parasitica var. nicotianae) et, d'autre part, l'ensemble des 8 espèces de Phytophthora non parasites incompatibles.

1. Les filtrats de culture en milieu PLICH dilués au $1 / 10$ entraînent, sur feuilles détachées de tabac, des réactions nécrotiques nulles avec les 5 souches du parasite mais très nettes avec l'ensemble des 15 souches de Phytophthora incompatibles. Ce résultat rejoint ceux obtenus par CSINOS \& HENDRIX avec les broyats mycéliens des espèces $P$. cryptogea, drechsleri et megasperma mais diffère des résultats de ces auteurs concernant la non-toxicité des espèces $P$. parasitica et $P$. cinnamomi. On peut supposer, d'une part, que les filtrats de culture ont une toxicité plus forte que les broyats mycéliens et que, d'autre part, la phytotoxicité d'un filtrat de culture est plus ou moins accusée suivant la technique de culture utilisée (milieu, durée, aération) ; c'est ce que semblent prouver les différences obtenues avec les mêmes souches cultivées de 2 manières différentes (tabl. $2 \mathrm{~B}$ ).

2. Le trempage racinaire des plants dans ces mêmes filtrats de culture permet la séparation des Phytophthora incompatibles en 2 groupes dont les réactions apparaissent quantitativement et qualitativement différentes (cf. $\S$ IIIB). On peut remarquer ici que le groupe des espèces fortement toxiques recoupe celui à réponses positives de CSINOS \& HENDRIX et que ces espèces, appartenant aux groupes V et VI de WATERHOUSE, sont essentiellement à développement souterrain, le plus souvent à large spectre d'hôtes et fréquemment associées lors d'étiologie de "dépérissements » d'espèces végétales ligneuses (DAvison \& BUMBIERIS, 1973 ; HOITINK \& SCHMITTHENNER, 1974 ; MARAIS, 1980 ; STANDISH et al., 1982). 

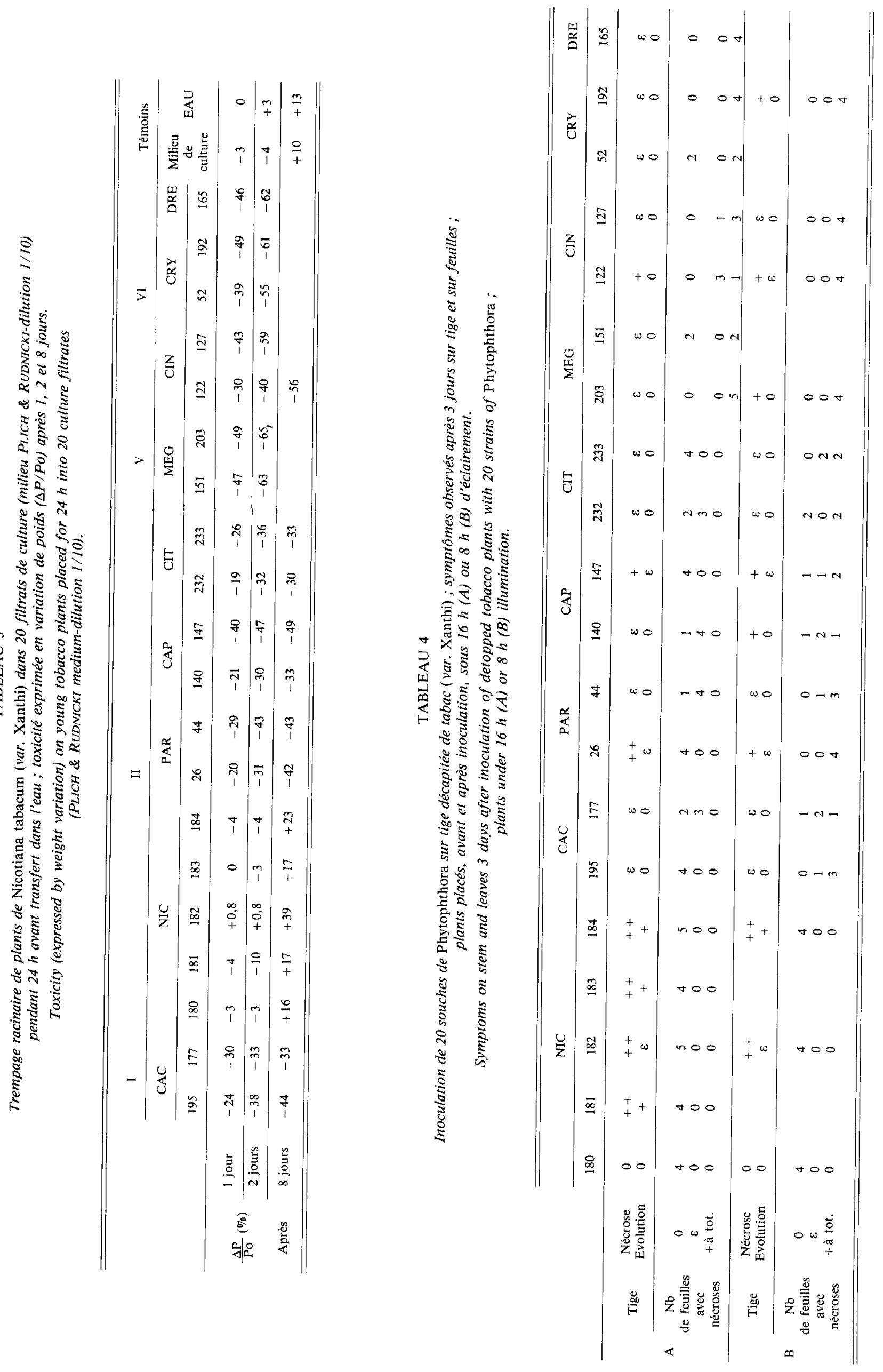
3. Enfin les inoculations des champignons sur tige décapitée de tabac donnent des résultats parallèles aux précédents ce qui semble écarter la possibilité d'un artefact lié aux conditions de la culture in vitro. Il faut noter, par contre, que l'apport de mycélium au sommet d'un plant décapité représente une inoculation beaucoup plus drastique que celle utilisée par CsINOS \& HENDRIX (inoculation sur le côté de la tige d'un plant intact) ce qui pourrait expliquer les divergences entre nos résultats et ceux de ces auteurs, surtout en ce qui concerne l'inoculation des espèces $P$. parasitica et cinnamomi. Quant à l'extériorisation plus accusée des symptômes sur plants soumis à un éclairement faible $(8 \mathrm{~h})$, on peut considérer que c'est un résultat rejoignant parfaitement les observations concernant l'effet de la lumière sur l'action toxique (CSINOS \& HENDRIX, 1977c).

Les résultats obtenus amènent, en conclusion, à se poser 2 types de questions :

- Les diverses espèces de Phytophthora non pathogènes sur tabac semblent toutes susceptibles d'induire des lésions nécrotiques foliaires, apparaissant à distance et plus ou moins violentes suivant les espèces considérées. A partir du filtrat de culture d'une souche de $P$. cryptogea - non pathogène mais fortement nécrosante - on a purifié un lipopeptide qui induit des symptômes toxiques identiques à ceux obtenus après inoculation ou apport du filtrat brut (BONNET et al., 1985). Peut-on dès lors envisager l'existence non plus de "pathotoxine" mais de " phytotoxine(s) " émise(s) par les souches incompatibles, entraînant chez la plante non-hôte des réactions violentes et cause(s) du rejet par la plante de la souche non parasite? Peut-on envisager l'existence de "phytotoxine(s) d'incompatibilité "?

- Ces réactions nécrotiques, liées à une invasion limitée de la plante par une espèce parasite non compatible, ne sont-elles pas à rapprocher des réactions de type hypersensible ? Dans ce cas, les réactions toxiques observées ne sont-elles pas le symptôme d'un bouleversement métabolique de la plante se traduisant par l'apparition de nouveaux métabolites, protéines b par exemple (GIANINAZZI \& AHL, 1983 ; VAN LOON, 1983), et par l'acquisition d'une certaine résistance à l'égard du pathogène?

\section{RÉFÉRENCES BIBLIOGRAPHIQUES}

Athanassiou I., Bonnet Ph., Ricci P., 1981. Expression du pouvoir pathogène chez le couple Phytophthora cryptogea-Gerbera. Agronomie, 1 (6), 495-502.

Bonnet Ph., Ricci P., Mercier S., 1980. Le dépérissement du Gerbera causé par Phytophthora cryptogea Pethybr, \& Laff. : Diagnostic à partir du matériel végétal par isolement et détermination rapide. Ann. Phytopathol., 12 (2), 109-118.

Bonnet Ph., Poupet A., Bruneteau M., 1985. Toxicité vis-à-vis du tabac des fractions purifiées d'un filtrat de culture de Phytophthora cryptogea Pethybr. \& Laff. Agronomie, 5 (3), 275-282.

Breiman A., Barash I., 1981. Partial characterization of phytotoxic compounds in culture filtrates of Phytophthora citrophthora. Phytopathol. Z., 102, 1-9.

Csinos A. S., 1979. Stem and foliar response of tobacco inoculated with Phytophthora spp. and Pythium myriotylum. Tob. Int., 181, 10, 97-99.

Csinos A., Hendrix J. W., 1977a. Nonparasitic stunting of tobacco plants by Phytophthora cryptogea. Can. J. Bot., 55, 26-29.

Csinos A., Hendrix J. W., 1977b. Laminar necrosis, growth inhibition, and death of tobacco plants caused by toxic extracts of Phytophthora cryptogea. Phytopathology, 67, 4, 434-438.

Csinos A., Hendrix J. W., 1977c. Toxin produced by Phytophthora cryptogea active on excised tobacco leaves. Can. J. Bot., 55, 9, 1156-1162.

Csinos A., Hendrix J. W., 1978. Phytophthora species producing toxin active on tobacco. Soil Biol. Biochem., 10, 1, 47-51.

Davison E. M., Bumbieris M., 1973. Phytophthora and Pythium spp. from pine plantations in South Australia. Aust. J. Biol. Sci., 26, 163-169.

Garibaldi A., 1975. Tentativi di lotta contro il marciume basale della Gerbera causato da Phytophthora cryptogea. Atti giornate fitopatol., 589-592.
Gianinazzi S., Ahl P., 1983. The genetic and molecular basis of $\mathbf{b}$ proteins in the genus Nicotiana. Neth. J. Plant Pathol., 89 (6), 275281.

Hendrix J. W., 1976. Inhibition of growth of tobacco plants by Phytophthora cryptogea. Tob. Sci., 20, 152-153.

Hoitink H. A., Schmitthenner A. F., 1974. Relative prevalence and virulence of Phytophthora species involved in Rhododendron root rot. Phytopathology, 64 (10), 1371-1374.

Marais A. G., 1980. Fungi associated with decline and death of nursery grapevines in the Western Cape. Phytophylactica, 12 (1), 9-13.

Middleton J. T., Tucker C. M., Tompkins C. M., 1944. A disease of Gloxinia caused by Phytophthora cryptogea. J. Agric. Res., 68, 405-413.

Orlikowski L. B., Rejman S., 1980. Effect of inoculum potential on severity of Phytophthora root rot of Gerbera. Pr. Inst. Sadow. Kwiac. Skier., Ser. B., 5, 141-150.

Plich M., Rudnicki R. M., 1979. Studies of the toxins of Phyophthora cactorum pathogenic to apple trees. I. Isolation, some of the properties and activities of a toxin produced by the fungus cultured in vitro. Phytopathol. Z., 94 (3), 270-278.

Scholten G., 1970. Wilt diseases in Gerbera. Neth. J. Plant Pathol., 76 (3), 212-218.

Standish E. D., MacDonald J. D., Humphrey W. A., 1982. Phytophthora root and crown rot of Juniperus in California. Plant Dis., 66 (10), 925-928.

Van Loon L. C., 1983. The induction of pathogenesis-related proteins by pathogens and specific chemicals. Neth. J. Plant Pathol, 89 (6), 265-273.

Waterhouse G. M., 1963. Key to the species of Phytophthora de Bary. Mycol. Pap., 92, 22 p. 